EGU21-10161, updated on 09 Feb 2022

https://doi.org/10.5194/egusphere-egu21-10161

EGU General Assembly 2021

(c) Author(s) 2022. This work is distributed under

the Creative Commons Attribution 4.0 License.

\title{
The continued accumulation of anthropogenic carbon in the global ocean during the 2010 s
}

\author{
Jens Daniel Müller ${ }^{1}$, Donghe Zhu ${ }^{1}$, Luke Gregor ${ }^{1}$, Are Olsen ${ }^{2}$, Nico Lange ${ }^{3}$, Siv Lauvset ${ }^{4}$, Toste \\ Tanhua $^{3}$, Masao Ishii ${ }^{5}$, Fiz Fernandez Perez ${ }^{6}$, Brendan Carter ${ }^{7,8}$, Richard Feely ${ }^{8}$, Rik Wanninkhof ${ }^{9}$, \\ and Nicolas Gruber ${ }^{1}$ \\ ${ }^{1}$ ETH Zurich, IBP, U-SYS, Zurich, Switzerland (jensdaniel.mueller@usys.ethz.ch) \\ ${ }^{2}$ Geophysical Institute, University of Bergen and Bjerknes Centre for Climate Research, Bergen, Norway \\ ${ }^{3}$ GEOMAR Helmholtz Centre for Ocean Research Kiel, Kiel, Germany \\ ${ }^{4}$ NORCE Norwegian Research Centre, Bjerknes Centre for Climate Research, Bergen, Norwa \\ ${ }^{5}$ Oceanography and Geochemistry Research Department, Meteorological Research Institute, Japan Meteorological Agency, \\ Tsukuba, Japan \\ ${ }^{6}$ Instituto de Investigaciones Marinas, IIM - CSIC, Vigo, Spain \\ ${ }^{7}$ Cooperative Institute for Climate, Ocean and Ecosystem Studies, University of Washington, Seattle, Washington, USA \\ ${ }^{8}$ Pacific Marine Environmental Laboratory, National Oceanic and Atmospheric Administration, Seattle, Washington, USA \\ ${ }^{9}$ Atlantic Oceanographic and Meteorological Laboratory, National Oceanic and Atmospheric Administration, Miami, USA
}

Surface ocean $\mathrm{pCO}_{2}$-based estimates and models indicate that the ocean sink for anthropogenic $\mathrm{CO}_{2}\left(\mathrm{C}_{\mathrm{ant}}\right)$ has continued to increase unabatedly over the past decade. However, the most recent global and observation-based estimate of the accumulation of $C_{\text {ant }}$ in the ocean interior by Gruber et al. (2019) does not extend beyond 2007, preventing an independent assessment of this increase in the magnitude of the sink.

Here, we exploit about 50,000 additional observations of dissolved inorganic carbon (DIC) and other relevant biogeochemical parameters, to extend the Gruber et al. analysis based on the eMLR(C*) method to the 2010s. These data were collected from all major ocean basins over the past decade by GO-SHIP and associated programs, and assembled through GLODAPV2.2020 into an internally consistent data product. We refine the $\operatorname{eMLR}\left(C^{*}\right)$ method in three ways to achieve the updated storage estimates: (1) the uncertainty assessment is improved, based on a coupled analysis of observations and synthetic data generated from an ocean biogeochemical model, (2) the robustness of the multiple linear regression models is increased, using more stringent predictor and model selection procedures, and (3) the mapping of the $C_{\text {ant }}$ fields relies on a MLR ensemble approach that takes into account co-occurring temporal changes of the predictor variables salinity, temperature and oxygen.

Initial results show that the ocean has continued to act as a strong $C_{\text {ant }}$ sink with an average uptake rate of $2.8 \pm 0.3 \mathrm{Pg} \mathrm{C} \mathrm{yr}^{-1}$ between the reference years 2007 and 2015 . This represents a small increase in rate compared to $2.6 \pm 0.3 \mathrm{Pg} \mathrm{C} \mathrm{yr}^{-1}$ determined for the 1994 through 2007 period. This increase is slightly smaller than expected on the basis of the growth of atmospheric 
$\mathrm{CO}_{2}$ over the period, but associated uncertainties are too large to make a conclusive statement about whether the ocean carbon sink is slowing down. Initial analyses of the synthetic data indicate that variable ocean circulation and limited sampling, especially the small number of cruises in the Indian Ocean, represent the biggest sources of uncertainty for the eMLR( $\left.C^{*}\right)$-based estimate. However, our preliminary sink estimate is in good agreement with recent air-sea $\mathrm{CO}_{2}$ flux-based uptake estimates, based on an ensemble of surface $\mathrm{pCO}_{2}$ interpolation techniques once these fluxes are adjusted for the river carbon input driven outgassing of natural $\mathrm{CO}_{2}$. 